\title{
EDITORIAL
}

\section{Overseas offices: a new attempt to disseminate Light}

\author{
Light: Science \& Applications (2017) 6, e16230; doi:10.1038/lsa.2016.230; published online 13 January 2017
}

$L^{2}$ ight: Science \& Applications (LSA) has established itself as a leading resource for the optics and photonics community within only four and a half years. In 2016, LSA received its third impact factor of 13.6, being listed as second among 90 journals in optics, according to the 2015 Journal Citation Reports from Thomson Reuters. In 2015, LSA published 70 papers, increased by $30 \%$ compared with 2014 , and the total citations rose by $65 \%$. In 2016, LSA received more than 700 papers from 35 countries and regions and published 84 papers, with a steady increase in submissions and publications over the years.

The long-term goal of LSA is to become an outstanding international journal in optics and photonics. We are approaching this step by step. However, we know that there is a long way ahead of us, and the efforts of several generations may be needed to achieve it. We are willing to exert our greatest efforts in this direction. We have been implementing various measures to enhance the quality and improve the impact of LSA. Today, a new attempt to set up LSA overseas offices is starting. Overseas offices will be based in local regions, covering neighboring areas, to perform activities relevant to LSA. The main responsibilities of overseas offices will include undertaking some of the manuscript processing workload to expedite the procedure, attending academic conferences relevant to optics, visiting outstanding scientists and leading research groups, hosting Light overseas forums, inviting high-quality papers, promoting $L S A$, etc.

In 2017, we plan to establish one or two overseas offices, located at the University of Rochester or the National University of Singapore. Each office is organized by one of the LSA editors. One full-time employee and one part-time staff member will be allocated. Some temporary workers or volunteers may also be recruited if needed. Furthermore, we hope to launch one additional overseas office each year during the next 5 years, with plans to establish regional offices for LSA around the world in the future.

This is a brand new attempt for LSA that has three objectives: (1) engage editors from all over the world to take active roles in the editorial work of LSA and make it easier for them to work for the journal. (2) Make full use of local resources to improve work efficiency and quality. (3) Push marketing and promotion by attending more conferences, visiting more research groups, hosting Light forums, and many other efforts. As the network hubs of LSA, overseas offices will become the seeds of $L S A$ to help make Light illuminate the world. With overseas offices, LSA will involve more scientists and research groups, thus providing a platform for free academic communication and exchange.

As stated above, we are planning to establish more overseas offices in different regions of the world. Anyone interested is welcome to join us. For details, please contact Dr Yuhong Bai (baiyh@ciomp.ac.cn), director of the Editorial Department at Changchun Institute of Optics, Fine Mechanics and Physics, Chinese Academy of Sciences. We hope that we will have the opportunity to work together for $L S A$ in the near future.

Jianlin Cao

Editor-in-Chief, Light: Science \& Applications, State Key Laboratory of Applied Optics, CIOMP, CAS, No. 3888, Dongnanhu Road, Changchun, China

Stefan Kaierle Executive Editor-in-Chief, Light: Science \& Applications, Laser Zentrum Hannover e.V. (LZH), Hannover 30419, Germany Email: s.kaierle@lzh.de

Tianhong Cui Executive Editor-in-Chief, Light: Science \& Applications, University of Minnesota, Minneapolis, MN 55455, USA Email: tcui@ciomp.ac.cn

\footnotetext{
(c) (i) $\odot$ This work is licensed under a Creative Commons Attributioncc. No ND Nommercial-NoDerivs 4.0 International License. The images or other third party material in this article are included in the article's Creative Commons license, unless indicated otherwise in the credit line; if the material is not included under the Creative Commons license, users will need to obtain permission from the license holder to reproduce the material. To view a copy of this license, visit http:// creativecommons.org/licenses/by-nc-nd/4.0/
}

(C) The Author(s) 2017 